\title{
The correlation of gestation period and the weight gain in low- birthweight newborns: the cases in perinatology ward of Regional Public Hospital of Banyumas
}

\author{
Ambarsih $^{1}$, Umi Solikhah ${ }^{2}$ \\ ${ }^{1,2}$ Department of Health, Muhammadiyah University of Purwokerto, Indonesia
}

\begin{tabular}{l} 
ARTICLE INFO \\
\hline Article history: \\
Received: August 9, 2020 \\
Revised: August 20, 2020 \\
Accepted: August 30, 2020 \\
\hline
\end{tabular}

\section{Keywords:}

Gestation Period, Baby, Low Birthweight

\begin{abstract}
The change of birth weight on low birthweight newborns reflects the nutrition condition or baby nutrition and related to the baby's immune system. Besides nutrition, the gestation period also affects weight gain on low birth weight newborns. This research to find out the correlation between the gestation period and weight gain on low birthweight newborns in the Perinatology ward of RSUD (Regional Public Hospital) Banyumas. This was quantitative research using an observational experimental design with the retrospective approach. There were 77 respondents as the samples of this research who were taken using a probability sampling technique of simple random sampling. The results showed that $47(61 \%)$ respondents were male. Most of the mothers or 70 respondents $(90.9 \%)$ were housewives. Most of them or 26 respondents (33.8\%) were Primary School graduates. The results of the linear regression test showed that the significance value on the variable of the gestation period was 0007 (p0.05). There was a correlation between the gestation period and weight gain on low birth weight newborns in the Perinatology ward of RSUD Banyumas.
\end{abstract}

This work is licensed under a Creative Commons Attribution 4.0 International License.

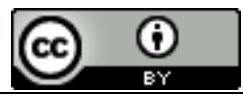

\section{Corresponding Author:}

Umi Solikhah,

Department of Health, Muhammadiyah University of Purwokerto,

Soepardjo Rustam Street KM. 7, Banyumas, Indonesia

Email: umisolikhah@ump.ac.id

\section{INTRODUCTION}

Maternal Mortality Rate (MMR) and Infant Mortality Rate (IMR) are indicators of health development in the National Long-Term Development Plan (RPJMN) of 2015-2019 and Suitable Development Goals (SDGs). According to the data of the Indonesian Health Demographic Survey (IDHS), the MMR has decreased for the period of 1994-2012, in 1994 with 390 case per 100,000 live births, and kept decreasing. It was only 334 in 1997, 307 in 2002, 228 in 2007. However, in 2012 the MMR went up dramatically to by 359 per 100,000 live births. For IMR, it can be said that the decline is on the track (continues to decline) and the 2012 IDHS shows the number was 32 per 100,000 live births.

The global prevalence of low birth weight (LBW) in the world is $15.5 \%$ (about 20 million cases), among $95 \%$ of them was from the developing countries. There is a significant variation of the LBW prevalence in several countries with the highest incidence in Central Asia (27.1\%) and the lowest in Europe (6.4\%).

LBW is triggered by several factors; this makes the preventive measures difficult to conduct. Its factors include maternal factors, placental factors, fetal factors, and environmental factors. Maternal factors include age, education, occupation, gestational distance, gestational age, parity, multiple pregnancy, hypertension, anemia, behavior. [1]

Infants with low birth weight have more potential to experience late cognitive development than the normal birth weight babies. [2] In addition, LBW has a 20 times greater risk of dying during the growing period compared to the normal (Organization Economic Central Foundation (OECD) and WHO). The incidence of LBW also contributes $60 \%-80 \%$ to neonatal mortality, so that it can have an indirect effect on 
infant mortality. In addition, the infant mortality rate tends to increase along with the increasing incidence of LBW in a country.

LBW can be induced by premature births and Intrauterine growth restriction (IUGR) (OECD and WHO). In addition, it can be inflicted by a variety of complex and interrelated factors, and the maternal factors are also known to influence the birth weight. [3]

One of the factors related to the birth weight is gestational period. Gestational period or gestational age is the time it takes for a mother from the conception to the birth. It is divided into three groups, namely early gestational age (pre-term) with gestational age $<38$ weeks, full gestational age (term) with gestational age 3842 weeks, and past gestation age (post-term) with gestational age $>42$ weeks. The classification of baby's birth weight can be done based on the mother's gestational age; it is divided into 3, namely small for gestational age (SGA), appropriate for gestational age (AGA), and large birth weight according to gestational age (large for gestational / LGA).

Change of body weight in LBW reflects the nutritional condition or nutrition of the baby and is closely related to the body power. LBW will lose weight in the first week of life by $10-15 \%$, but it will increase at the age of 10-14 days at 25-30 grams per day for 3 months. Whereas BBLSR? will lose weight for 7-10 days of life by $10-15 \%$, and it will return again at the age of 10-14 days. [4]

Apart from nutrition, the factor of gestation can affect the baby's weight gain at LBW. The relationship between gestational age and the birth weight can occur due to several possibilities, namely low birth weight due to relatively early gestational age, low birth weight with normal gestational age, and a combination of the two possibilities. [5] A study indicated that mothers with a relatively early gestational age had a tendency to give birth to LBW babies with a risk of 4 times greater than mothers with a full gestational age. [6]

Based on a preliminary study in the Perinatology ward of Banyumas Hospital, it shows that there were 338 cases of low newborns from January to June 2019. Most of them were treated in the perinatology room and the NICU. Based on this result and the phenomena in the field, the authors are interested in doing this study. This is to determine the relationship between gestation and weight gain in low-weight newborns in the Perinatology room of Banyumas Hospital.

\section{RESEARCH METHOD}

This is a quantitative research, with a non-experimental, observational analytic research design with a retrospective approach. The sample used in this study was 77 , with a probability sampling technique using simple random sampling in accordance with the inclusion and exclusion criteria. The data analysis used in this research is the linier regression.

\section{RESULT AND DISCUSSIONS}

\subsection{Characteristics of the Respondents}

Table 1. The distribution of parental respondent characteristics based on: age, parity, level of education, job, and birth weight based on gestation in the Perinatology room of Banyumas Hospital.

\begin{tabular}{lc}
\hline Variable & Results \\
\hline Mothers' characteristics & \\
Job & $3(3,9 \%)$ \\
Teacher & $70(90,9 \%)$ \\
Housewife & $3(3,9 \%)$ \\
Employee & $1(1,3 \%)$ \\
Trader & \\
Education & $26(33,8 \%)$ \\
Primary School & $23(29,9 \%)$ \\
Junior High School & $22(28,6 \%)$ \\
High school & $3(3,9 \%)$ \\
Diploma & $3(3,9 \%)$ \\
Undergraduate & \\
Gestation period & $35,06 \pm 2,597$ \\
Mean \pm SD & $29-41$ \\
Min-Max & \\
Parity & $2,21 \pm 1,196$ \\
Mean \pm SD & $1-6$ \\
Min-Max & \\
Mothers'age & $30,06 \pm 6,940$ \\
Mean \pm SD &
\end{tabular}




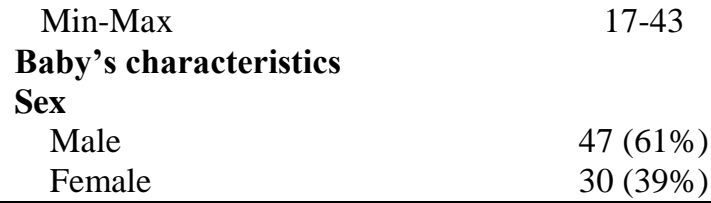

Based on table 1, it shows that the mean of the gestation period of pregnant women is 35.06 weeks with a standard deviation of 2.597 and a minimum period of 29 weeks, a maximum period of 41 weeks. The average of the birth rate or parity is 2.21 with a standard deviation of 1.196 and a minimum number of births of 1 and a maximum of 6 . The average age of the pregnant women is 30.06 years with a standard deviation of 6.940 and a minimum age of 17 years and a maximum of 43 years. Most of the sex of babies is $61 \%$ (47), most of the mothers are housewives, 70 (90.9\%). Most of them are only at at the primary education, $26(33.8 \%)$.

\subsection{The Relationship of Gestation Period, Parity and Age with Low Weight Gain of the Newborns in the Perinatology Room of Banyumas Hospital}

Table 2. The Relationship Between Gestation Period and Low Weight Gain in Newborns in the Perinatology Room at Banyumas Hospital

\begin{tabular}{|c|c|c|c|c|}
\hline Variable & & $\mathbf{t}$ & B & p-value \\
\hline Gestation period & & & & \\
\hline $\begin{array}{l}\text { Mean } \pm \text { SD } \\
\text { Min-Max }\end{array}$ & $\begin{array}{c}35,06 \pm 2,597 \\
29-41\end{array}$ & 2,801 & 10,689 & 0,007 \\
\hline
\end{tabular}

Based on the table above, the mean gestation period of pregnant women is $35.06 \pm 2.597$ with a minimum gestation period of 29 weeks and a maximum of 41 weeks. The results of bivariate analysis using linear regression test show t value of 2.801 and a significance value of 0.007 ( $p<0.05)$. It means there is a relationship between gestation period and low weight gain in newborns in the Perinatology room of Banyumas Hospital. The B value of 10.689 means that the normal gestation period of pregnant women $>35.06$ weeks has a tendency to experience weight gain in infants who experience LBW 10.689 times higher than mothers who have a gestation period of $<35.06$ weeks.

Gestational period (gestational age) is a general term used during pregnancy to describe how far the pregnancy has progressed and is measured in weeks, from the first day of a woman's menstrual cycle to a certain time. [7] Based on the results of the analysis, it is known that the mean gestation period of pregnant women is 35.06 weeks or occurs at $<37$ weeks' gestation. Babies born at $<37$ weeks' gestation can be classified as preterm infant (premature babies). [8] The incidence of preterm birth in Indonesia is still quite high, where in 2010 Indonesia was ranked 9th out of 10 countries with the highest rate of preterm birth in the world, which is 15.5 per 100 child births. The high incidence of preterm birth and technological advances, an increase in the birth of premature babies born alive can have an effect on the increase in the number of LBW children. [9]

During this gestation period, adequate nutritional intake is required to meet the nutritional needs for a perfect fetal development. [10] The condition of poor nutritional intake during pregnancy is one of the risk factors for less weight gain in infants with low birth weight. [11] One indicator to determine the nutritional status of the mother is through the size of the upper arm circumference (LiLA) $\leq 23.5 \mathrm{~cm}$, where it can be used to determine the state of long-term (chronic) energy deficiency in women of childbearing age (WCA) and pregnant women.

\section{CONSLUSION}

The mean gestation period of pregnant women is 35.06 weeks, the average birth or parity is 2 and the average age of pregnant women is 30.06 years. Most of the sex of the babies is male (47 or $61 \%$ ). Most of the mothers are housewives, 70 respondents (90.9\%). Most of their education levels are at the primary school level, $26(33.8 \%)$. From the statistical calculation, it is concluded that there is a significant relationship between gestation period and low weight gain in newborns in the Perinatology Room at Banyumas Hospital.

\section{Acknowledgements}

Thank you for the support from the Director of Banyumas Hospital who facilitate the data collection in Banyumas Hospital. Thanks to the Head of the Medical Record Installation and other health workers who have helped in the data collection process in this study. 


\section{REFERENCES}

[1] M. S. P. G. P. Pramono, "Risiko Terjadinya Berat Bayi Lahir Rendah Menurut Determinan Sosial, Ekonomi dan Demografi di Indonesia.," Buletin Penelitian Sistem Kesehatan, no. 12, pp. 127-132, 2010.

[2] U. C. I. ,. O. O. A. Abanihe, "Maternal and Environment Factors Influencing Infant Birth Weight in Ibadan, Nigeria.," African Population Studies, vol. 2, no. 25, pp. 250-267, 2011.

[3] K. H. K. G. \&. B. K. Viswanatha, "Factors affecting low birth weight at four central hospitals in Vientiane," no. 72, pp. 51 - 58, 2014.

[4] L. \&. Y. Y. Viengsakhone, “Factors affecting low birth weight at four central hospitals in Vientiane, Lao PDR. Nagoya,” no. 72, pp. 51 - 58, 2010.

[5] H. B. Nejad, "The Incidence of Low Birth (LBW) AND Small-for-Gestational Age (SGA) and its Related Factors in Neonates, Sabzevar, Iran.," vol. 2, no. 6, pp. 73-78., 2014.

[6] U. C. I. \&. O. O. A. Abanihe, “Maternal and Environment Factors Influencing Infant Birth Weight in Ibadan, Nigeria.," African Population Studies, vol. 2, no. 25, pp. 250-267, 2011.

[7] "National Institute of Health. Gestational age [Online]," 2013. [Online]. Available: http://www.nlm.nih.gov/medlineplus/ency/article/002367.html. [Diakses 10 Agustus 2019 ].

[8] N. T. Hatfield, Introductory Maternity and Pediatric Nursing, 3rd penyunt., China: Wolters Kluwer Health dan Lippincott Williams and Wilkins., 2014.

[9] R. Sutan, “ Determinant of Low Birth Weight Infants: A Matched Case Control Study., Journal of Preventive Medicine, vol. 4:, pp. 91-99., 2014.

[10] K. \&. F. D. Abu-Saad, “ Maternal Nutrition and Birth Outcomes,” Oxford Journal, vol. 32 , pp. 5-25, 2010.

[11] M. T. J. Martin, “Births: Final Data for 2012,” National Vital Statistic Report, p. 62, 2013. 